\title{
A Satellite-based Remote Sensing Technique for Surface Water Quality Estimation
}

\author{
Michelle V. Japitana \\ School of Engineering, University of San Carlos, Cebu City \\ and College of Engineering and GeoSciences, Caraga State \\ University, Butuan City, Philippines \\ mvjapitana@carsu.edu.ph
}

\author{
Marlowe Edgar C. Burce \\ School of Engineering, \\ University of San Carlos \\ Cebu City, Philippines \\ mcburce@yahoo.com
}

\begin{abstract}
Remote sensing provides a synoptic view of the earth surface that can provide spatial and temporal trends necessary for comprehensive water quality (WQ) monitoring and assessment. This study explores the applicability of Landsat 8 and regression analysis in developing models for estimating WQ parameters such as $\mathrm{pH}$, dissolved oxygen (DO), total dissolved solids (TDS), total suspended solids (TSS), biological oxygen demand (BOD), turbidity, and conductivity. The input image was radiometrically-calibrated using fast line-of-sight atmospheric analysis (FLAASH) and then atmospherically corrected to obtain surface reflectance (SR) bands using FLAASH and dark object subtraction (DOS) for comparison. SR bands derived using FLAASH and DOS, water indices, band ratio, and principal component analysis (PCA) images were utilized as input data. Feature vectors were then collected from the input bands and subsequently regressed together with the WQ data. Forward regression results yielded significant high $R^{2}$ values for all WQ parameters except TSS and conductivity which had only $60.1 \%$ and $67.7 \%$ respectively. Results also showed that the regression models of $\mathrm{pH}, \mathrm{BOD}$, TSS, DO, and conductivity are highly significant to SR bands derived using DOS. Furthermore, the results of this study showed the promising potential of using RSbased WQ models in performing periodic WQ monitoring and assessment.
\end{abstract}

Keywords-spectral; reflectance; radiance; water quality modelling; geoinformatics

\section{INTRODUCTION}

Water is among the most important resources. However, water bodies are under acute seasonal scarcity due to the increased rate of human intervention and human-induced modification of natural processes [1]. Periodic monitoring and assessment of water quality (WQ) help to develop management strategies to control surface water pollution [2]. Governmentsponsored WQ monitoring programs usually employ field measurements and collection of water samples for subsequent laboratory analysis in a traditional way. While such conventional approach to WQ monitoring data is accurate at a specific location and time, in most cases, it cannot provide enough information on overall WQ. Water monitoring data and reports in the Philippines usually only have point-specific datasets which lack spatiotemporal trends that are rather vital in the monitoring, assessment, and identification of water management strategies. Also, though this in-situ measurement offers high accuracy, it is not feasible to provide a simultaneous WQ database on a regional scale [3]. Fortunately, the emerging technologies of geoinformatics, particularly remote sensing (RS) and geographic information system (GIS), provide useful tools for a comprehensive WQ assessment and management. Remote sensing datasets offer a synoptic view of ongoing earth surface processes which allows an evaluation of the pressures placed on aquatic ecosystems [4]. Scientific findings towards understanding WQ by employing RS techniques are highly effective. Such techniques are valuable in monitoring upstream land use and land cover changes and spread [5], deriving RS empirical models to aid WQ monitoring and assessment[2, 6-8], and mapping the spatial distribution of WQ parameters using GIS [2, 9]. Moreover, satellite images have been used successfully in water management protocols such as to conduct inventory and water balance assessment [10-12], to assess flood areas [13], and for WQ change detection and monitoring $[14,15]$.

There is no restriction on obtaining and using Landsat satellite imagery [16]. Landsat satellite series are widely used to establish relationships between WQ parameters of surface waters and spectral reflectance [17-20]. Authors in [21] showed that satellite-based regression models can be derived using images acquired with a maximum of \pm 15 days offset from the date of in-situ water sampling. However, there are recommendations of a narrower time difference of \pm 5 days [22], \pm 4 days [23], \pm 3 days [21], and \pm 1 day [22, 24] between the sampling date and the acquisition date of the image. For this study, an offset of \pm 5 or lesser days is set in the selection of satisfactory (less cloud cover) satellite images. Regression analysis is one of the widely used methods to determine spectral reflectance and WQ parameter relationship by selecting derived regression models with high $\mathrm{R}^{2}$ value $[6,16$, $19,25]$. A wide range of studies proved the potential of using satellite datasets in deriving WQ models which include physicochemical water parameters $[18,24,26]$, nutrient concentrations [20], and heavy metals [27]. For instance, authors in [17] applied regression modelling to develop algorithms for estimating TSS, pH, BOD, and chlorophyll-a. Hence, in this study, WQ algorithms are developed using a combined regression and remote sensing approach. The objective of this study is to determine the potential of using 
Landsat 8 images combined with field measurements to predict selected WQ indicators. To derive WQ regression models, this study utilizes various raw, pre-processed, and post-processed Landsat 8 bands and in-situ WQ data and employs regression analysis.

\section{STUDY AREA}

Tubay River is one of the principal rivers in Agusan del Norte, Philippines which is classified as a Class A water body. Its headstream is the main outlet of Lake Mainit, and the river traverses within the municipalities of Jabonga, Santiago, and Tubay. There are two major tributaries of the river, one at its upstream portion and the other at the mid-downstream part. The river plays a vital role in the economic development of the said municipalities, as manifested by its diverse uses that include irrigation and other agricultural uses, fisheries, livestock production, and various domestic uses and tourism. The river is also a receptor of domestic solid and liquid wastes and other non-point sources of polluted waters [28]. Figure 1 shows the location of Tubay River and the terrain within the study area.
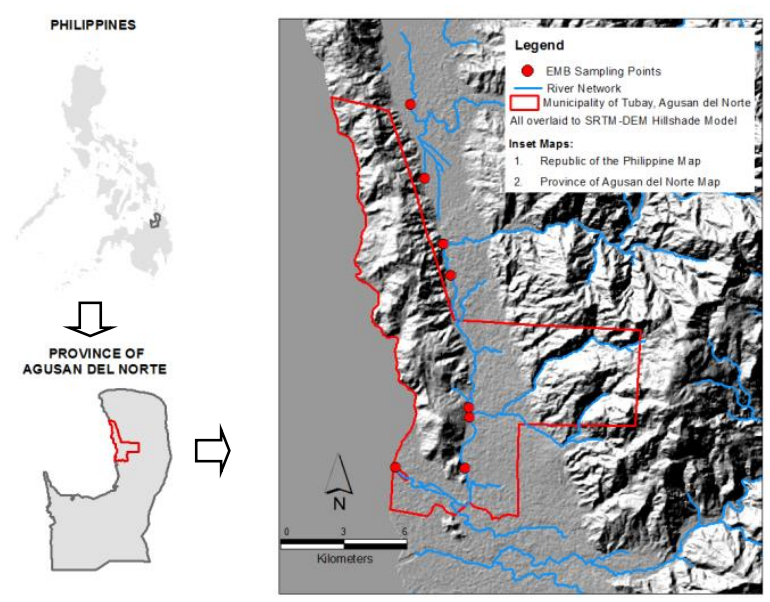

Fig. 1. The study area showing the location of Tubay, Agusan del Norte and the location of EMB water quality monitoring points.

\section{MATERIALS AND METHODS}

The 2014-2015 WQ monitoring data of the Environmental Management Bureau (EMB) were utilized in this study. To explore the relationships between WQ indicators and spectral data, we employed the latest addition in the Landsat series which is the Landsat 8 OLI. Landsat 8 images with acquisition dates with a \pm 5 -day difference to the water sampling dates of the EMB were downloaded through USGS Earth Explorer. The general methodology applied in this study is shown in Figure 2.

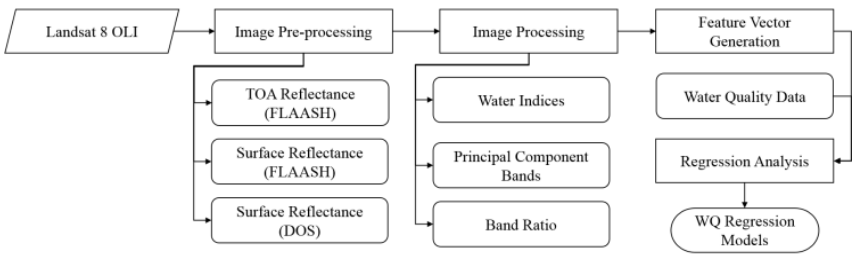

Fig. 2. High level abstraction of processes and data flow.

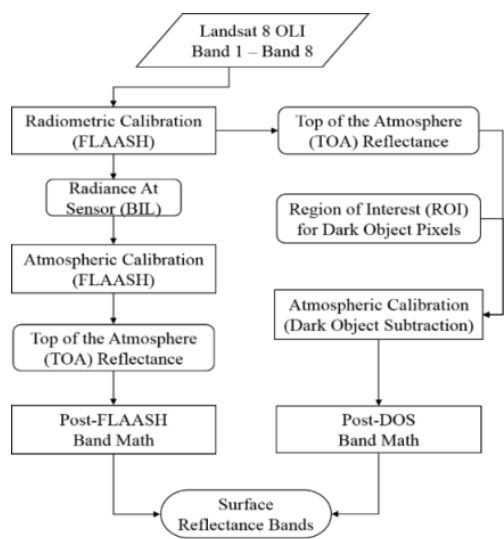

Fig. 3. The procedure flow for pre-processing the Landsat 8 OLI image.

In the pre-processing part, we employed radiometric correction to remove errors in the raw pixel values (digital numbers, DN) of the Landsat image and convert the pixels into radiance or reflectance using the FLAASH tool. A detailed procedure of transforming $\mathrm{DN}$ into at-sensor radiance and surface reflectance is covered entirely in [29]. The general form of the equation for computing TOA Reflectance (RTOA) is shown in (1) and (2):

$$
\begin{aligned}
& L_{\lambda}^{\prime}=M_{\rho} * Q C A L+A_{\rho} \\
& L_{\lambda}=L_{\lambda}^{\prime} / \cos \theta_{S E}
\end{aligned}
$$

where $L_{\lambda}^{\prime}$ is TOA spectral radiance, $Q C A L$ is the quantized calibrated pixel values in DN, $M_{\rho}$ is the band-specific multiplicative rescaling factor, band-specific $A_{\rho}$ is the additive scaling factor, $\theta_{S E}$ is the local sun elevation angle, and $L_{\lambda}$ is the TOA reflectance.

Then, atmospheric correction was employed to transform TOA radiance or reflectance bands into surface reflectance using two types of pre-processing methods to investigate which method is the most appropriate for extracting RS-based WQ models. The first method is to apply the FLAASH atmospheric correction [30] automatically while the second method employs DOS [31]. Band math computations were finally applied to surface reflectance bands using the two approaches to complete the post-FLAASH and post-DOS procedure. Then the raw, radiance and reflectance images were used to perform PCA and band ratios for deriving two water indices. To enhance the spectral appearance of water bodies, modified normalized difference water index (MNDWI) and normalized difference water index (NDWI) variants were derived using (3)-(5). Band ratio (BR) was also obtained using Band 1 and Band 5 by applying (6):

$$
\begin{aligned}
& M N D W I=\left(\rho_{3}-\rho_{6}\right) /\left(\rho_{3}+\rho_{6}\right) \\
& N D W I_{1}=\left(\rho_{3}-\rho_{5}\right) /\left(\rho_{3}+\rho_{5}\right) \\
& N D W I_{2}=\left(\rho_{5}-\rho_{6}\right) /\left(\rho_{5}+\rho_{6}\right) \\
& B R=\rho_{1} / \rho_{5}
\end{aligned}
$$

where $\rho_{1}$ is the ultra-blue (coastal/aerosol) band, $\rho_{3}$ is the green band, $\rho_{5}$ is the NIR band, and $\rho_{6}$ is the SWIR 1 band of the Landsat 8 OLI image. 
All images were then resized to contain only the region of Tubay River as study area. We then extracted feature vectors from each raw image and transformed satellite images using the geographic locations of the monitoring stations of EMB. Then, all pixel values were organized and tabulated to be used for regression analysis. During the regression, two fitting methods were applied using the SPSS 16.0 software, the enter method and the forward (step-up) method. In the first method, all variables with high correlation to the WQ parameter are fitted in the regression model while the forward method only includes variables that explain a significant amount of additional variance in the model and output all possible regression models with significant $R^{2}$ values.

\section{EXPERIMENTAL RESULTS}

Quarterly WQ monitoring data for the years 2014 and 2015 were available during this study. From these datasets, only 7 physical WQ parameters were considered during this study: $\mathrm{pH}, \mathrm{DO}, \mathrm{BOD}, \mathrm{TSS}, \mathrm{TDS}$, conductivity and turbidity. Among the available satellite images in the study area, only the Landsat 8 OLI images acquired during April 19, 2015 were utilized since they qualified the \pm 5 day difference and the minimal cloud cover criteria. Hence, the EMB April 14, 2015 WQ data (shown in Table I) were utilized for statistical RS modelling. A total of 7 raw bands, 7 pre-processed bands using FLAASH, 7 pre-processed bands using DOS, 18 principal component (PC) bands, 3 water indexes, and 1 BR were used in this study. This results in a total of 43 variables to be considered in the regression analysis. Statistical results showed that 6 variables or image bands were found to be highly correlated to all physical under consideration WQ parameters. These variables include mostly image bands atmospherically corrected using DOS. These variables were fitted in the respective WQ regression models using the enter method in SPSS which all resulted to an $\mathrm{R}^{2}$ value of $100 \%$. Table II shows all the regression models (enter method) derived using various RS datasets.

TABLE I. WATER QUALITY DATA OF TUBAY RIVER, APRIL 14, 2015

\begin{tabular}{|c|c|c|c|c|c|c|c|}
\hline Stn. & $\begin{array}{c}\text { DO } \\
(\mathbf{m g} / \mathbf{L})\end{array}$ & $\begin{array}{c}\text { BOD } \\
(\mathbf{m g} / \mathbf{L})\end{array}$ & $\begin{array}{c}\text { TSS } \\
(\mathbf{m g} / \mathbf{L})\end{array}$ & $\begin{array}{c}\text { TDS } \\
(\mathbf{m g} / \mathbf{L})\end{array}$ & $\mathbf{p H}$ & $\begin{array}{c}\text { Conductivity } \\
(\mathbf{m S} / \mathbf{c m})\end{array}$ & $\begin{array}{c}\text { Turbidity } \\
(\mathbf{N T U})\end{array}$ \\
\hline 1 & 7.3 & 0.7 & 5 & 1,510 & 7.65 & 2.25 & 1.21 \\
\hline 2 & 7.8 & 0.7 & 4 & 112 & 7.93 & 1.72 & 81.6 \\
\hline 3 & 8.1 & 0.8 & 8 & 116 & 7.95 & 0.165 & 85.3 \\
\hline 4 & 8.0 & 0.8 & 24 & 86 & 8.20 & 0.125 & 92.5 \\
\hline 5 & 7.4 & 0.6 & 12 & 92 & 8.03 & 0.140 & 66.3 \\
\hline 6 & 7.4 & 0.7 & 0.0 & 97 & 8.03 & 0.149 & 51.0 \\
\hline 7 & 7.6 & 0.5 & 48 & 97 & 8.14 & 0.149 & 55.3 \\
\hline
\end{tabular}

Source: EMB (2015)

The first run of forward regression analysis did not output a statistical model for DO and turbidity. In this method, out of the 6 significant variables identified in previously, only 3 were found to be substantial in the derived WQ regression models. These are the BR, PC4 of surface reflectance bands calibrated using DOS (PC4_SR 2 ), and the PC5 of surface reflectance bands calibrated using FLAASH (PC5_SR 1$)$. Forward regression analysis results showed that the models for TDS, BOD, and $\mathrm{pH}$ yielded the highest $\mathrm{R}^{2}$ values of $96.8 \%, 89.3 \%$, and $89.0 \%$, respectively. The resulting regression models also showed the strong association of BR to water $\mathrm{pH}$, TDS, and conductivity. Also, the PC reflectance band 4 is highly significant to both BOD and TSS regression models, although the $\mathrm{R}^{2}$ value of the TSS regression model is only $60.1 \%$. Moreover, forward regression analysis for TDS resulted in two models. The first model with the highest $\mathrm{R}^{2}$ value of $96.8 \%$ has $\mathrm{BR}$ and PC1_SR 1 as predictors while the second model shows that TDS can also be estimated using only BR as a predictor with an $\mathrm{R}^{2}$ value of $77.6 \%$.

TABLE II. REMOTE SENSING-BASED REGRESSION MODELS (ENTER METHOD) FOR SELECTED WQ PARAMETERS.

\begin{tabular}{|c|c|c|c|}
\hline $\begin{array}{c}\text { Model } \\
\text { No. }\end{array}$ & Dependent & Predictors and coefficients & $\mathbf{R}^{2} \%$ \\
\hline 1 & DO & 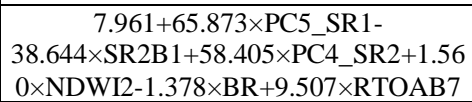 & 100 \\
\hline 2 & $\mathrm{pH}$ & 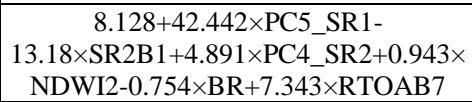 & 100 \\
\hline 3 & BOD & $\begin{array}{c}0.285+10.063 \times \text { PC5_SR1- } \\
7.258 \times \text { SR2B1+32.07 } 1 \text { PC4_SR2+0.573 } \times \\
\text { NDWI } 2+0.017 \times \text { BR }+3.089 \times \text { RTOAB7 }\end{array}$ & 100 \\
\hline 4 & TSS & 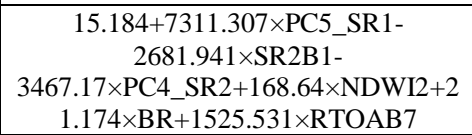 & 100 \\
\hline 5 & TDS & 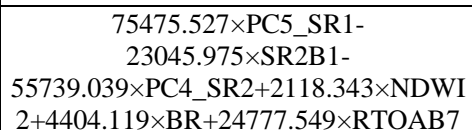 & 100 \\
\hline 6 & Turbidity & $\begin{array}{c}183.783+3031.118 \times \text { PC5_SR1- } \\
480.841 \times \text { SR2B1+4903.518×PC4_SR2- } \\
64.447 \times \text { NDWI2-258.509×BR- } \\
681.372 \times \text { RTOAB7 }\end{array}$ & 100 \\
\hline 7 & Conductivity & $\begin{array}{c}2.726+18.552 \times \text { PC5_SR1+33.248×SR2B } \\
1-110.85 \times \text { PC4_SR2- } \\
12.795 \times \text { NDWI2+2.775 } \times \text { BR- } \\
19.44 \times \text { RTOAB7 }\end{array}$ & 100 \\
\hline
\end{tabular}

$\mathrm{SR}_{1}=$ surface reflectance bands calibrated using post-FLAASH, $\mathrm{SR}_{2}=$ surface reflectance bands calibrated using post-DOS, B\#=band number, $\mathrm{PC}=$ principal component

Then, we evaluated back the WQ datasets for DO and turbidity since the first run of the forward regression analysis did not yield models for these WQ parameters. The WQ data in Table I showed that it has the lowest level (1.21) of turbidity at Station 1 which is located at the mouth of the river. This suggests low flows during the measurement and that the water was relatively clear. This situation is also evident even 5 days after the WQ measurement as shown in the zoomed-in images (true color image and histogram-stretched true color image) from the Landsat (Figure 4). At the mouth of the river, we can observe in Figure 4(a) that the pixels depict greenish color while it is light blue in Figure 4(b). In the upper stream of the river, turbid water appears dark (near black) in the normal RGB image. On the other hand, it is very dark blue in the enhanced RGB image applied with histogram equalization.

TDS level at Station 1 is extremely high and exceeds the $1000 \mathrm{mg} / \mathrm{L}$ minimum standard. This TDS concentration may indicate pollution and may pose danger to aquatic life. The TDS is a measure of dissolved solid materials in the river water that includes salts, some organic materials, and a wide range of other things from nutrients to toxic substances [32]. Despite the high concentration of TDS at Station 1, its DO level passed the minimum criteria of DENR, indicating that there is enough 
amount of oxygen dissolved in the water to support aquatic life. The very extreme turbidity and TDS values in Station 1 may indicate a different scenario since Station 1 is located at the mouth of the river. To avoid any uncertainties during the modelling process, Station 1 data for turbidity and TDS were excluded. Considering the relationship between WQ parameters, we also included them in each run of the regression analysis. Indeed, a new set of regression models were derived for DO and Turbidity. Table III shows all the derived RS-based models using regression analysis (forward method) including DO and turbidity.

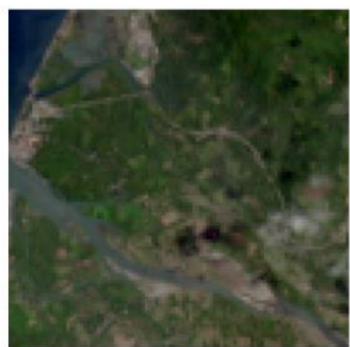

(a)

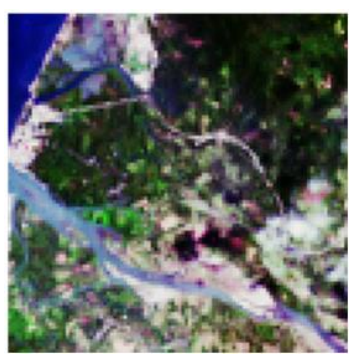

(b)
Fig. 4. The subset or zoomed in images of Landsat 8 acquired April 19, 2015, showing the downstream river: (a) true color RGB image (b) enhanced true color RGB composite image by employing histogram equalization.

TABLE III. REMOTE SENSING BASED REGRESSION MODELS (FORWARD METHOD) FOR SELECTED WQ PARAMETERS.

\begin{tabular}{|c|c|c|c|c|}
\hline $\begin{array}{c}\text { Model } \\
\text { No. }\end{array}$ & Dependent & $\begin{array}{c}\text { Predictors and } \\
\text { coefficients }\end{array}$ & $\mathbf{R}^{2} \%$ & $\begin{array}{c}\text { Standard } \\
\text { estimate error }\end{array}$ \\
\hline 1 & DO & $\begin{array}{c}7.446+0.008 \times \\
\text { Turbidity- } \\
11.59 \times \mathrm{SR}_{2} \mathrm{~B} 1 \\
\end{array}$ & 88.5 & 0.828 \\
\hline 2 & $\mathrm{pH}$ & $8.339-0.827 \times \mathrm{BR}$ & 89.0 & 0.060 \\
\hline 3 & BOD & $\begin{array}{c}0.382+28.746 \times \mathrm{PC} 4 \\
{ }_{-} \mathrm{SR}_{2}\end{array}$ & 90.0 & 0.041 \\
\hline 4 & TSS & $\begin{array}{c}53.257- \\
3633.719 \times \mathrm{PC} 4 \_\mathrm{SR}_{2}\end{array}$ & 60.1 & 11.55 \\
\hline 5 & TDS & $\begin{array}{c}\text { 90.124- } \\
\text { 1911.396×PC6_SR } 1 \\
\end{array}$ & 84.6 & 5.113 \\
\hline 6 & TDS & $\begin{array}{c}\text { 84.734- } \\
\text { 3465.448×PC6_SR }+4 \\
07.034 \times \text { PC3_SR }\end{array}$ & 99.5 & 1.025 \\
\hline 7 & Turbidity & $\begin{array}{c}37.985 \times \mathrm{DO}+4742.646 \\
\times \mathrm{PC} 5 \_\mathrm{SR}_{1-} \\
295.309 \times \mathrm{PC} 3 \mathrm{SR}_{1^{-}} \\
42.973 \times \mathrm{PC} 2 \_\mathrm{SR}_{2^{-}} \\
220.624\end{array}$ & 100.0 & 0.026 \\
\hline 8 & Turbidity & $\begin{array}{c}39.985 \times \mathrm{DO}+4548.48 \\
6 \times \mathrm{PC} 5 \_\mathrm{SR}_{1^{-}} \\
213.951 \times \mathrm{PC} 3 \_\mathrm{SR}_{1^{-}} \\
228.288\end{array}$ & 99.8 & 1.051 \\
\hline 9 & Turbidity & $\begin{array}{l}36.176 \times \mathrm{DO}+3334.53 \\
6 \times \mathrm{PC} 5 \_\mathrm{SR}_{1}-198.601 \\
\end{array}$ & 96.5 & 4.076 \\
\hline 10 & Conductivity & $3.682 \times$ BR -0.882 & 67.7 & 0.570 \\
\hline
\end{tabular}

The DO regression model yielded an $\mathrm{R}^{2}$ of $88.5 \%$ with turbidity and surface reflectance Band 1 derived using postDOS method $\left(\mathrm{SR}_{2} \mathrm{~B} 1\right)$ as predictors, while the regression for turbidity resulted in 3 models with very high $\mathrm{R}^{2}$ of $100 \%$, $99.8 \%$, and $96.5 \%$, respectively. The regression model for turbidity with highest $\mathrm{R}^{2}=100 \%$ has 4 predictors which are $\mathrm{PC}$ 3 and PC 5 of surface reflectance bands corrected using postFLAASH method (PC3_SR 1 and PC5_SR 1 ), DO, and PC 2 of surface reflectance bands corrected using DOS method $\left(\mathrm{PC} 2 \mathrm{SR}_{2}\right)$. With these regression modelling results for turbidity and DO, the significant predictors that were included in the models confirmed the high correlations found between turbidity and DO. As observed in Table II, using enter regression, 4 of the most significant variables are band images applied with post-DOS correction and its derivatives (e.g., $\mathrm{PCA}, \mathrm{NDWI}_{2}$, and $\mathrm{BR}$ ). In particular, these are the surface reflectance Band 1, PC Band 4, $\mathrm{NDWI}_{2}$, and $\mathrm{BR}$ and then, 2 more bands, TOA Reflectance Band 7 and PC 5 of surface reflectance, using Post-FLAASH (PC5_SR 1 ). This implies that the surface reflectance bands processed using post-DOS correction, the TOA Reflectance Band 7, and PC5_SR 1 are practically useful in developing WQ algorithms using enter regression analysis. However, in Table III, when forward regression analysis was employed, only 1 to 2 image bands were found to be significant for each RS-based WQ model. Two of the 6 significant bands (i.e. TOA Reflectance Band 7 and the $\mathrm{NDWI}_{2}$ ) using enter regression were already not included as predictors in the models determined by forward regression analysis. It can be observed that the resulting predictors of each regression model can be easily associated with the type of calibration method used. For example, the RSbased regression models for $\mathrm{pH}, \mathrm{BOD}, \mathrm{TSS}, \mathrm{DO}$, and conductivity involve predictors representing image bands derived using post-DOS calibration. The second regression model for TDS, on the other hand, involved surface reflectance bands derived from both post-DOS and post-FLAASH. While TDS ( $1^{\text {st }}$ model) and turbidity regression models include image bands derived using post-FLAASH method.

Regarding the goodness of fit, WQ models obtained remarkable $\mathrm{R}^{2}$ values except TSS and conductivity with $60.1 \%$ and $67.7 \%$, respectively. This proves the potential of employing image processing and regression modelling in deriving RS-based WQ models. We compared the performance of the developed models in this study to other regression models derived from remote sensing data with moderate resolution like Landsat series [14, 16, 19, 23], and from other satellite sensors with high resolutions like Worldview-2 [18] and ASTER [26]. We also took note of the atmospheric correction method and other post-processing techniques. As observed in Table IV, the $\mathrm{R}^{2}$ values of the algorithms developed in this study for $\mathrm{pH}$, turbidity, TSS, and BOD are better than the ones from the other models presented in previous studies using Landsat images. This holds true even when our developed models for $\mathrm{DO}, \mathrm{pH}$, and TSS are compared to regression models based on a 2-meter resolution Worldview-2 image. It is interesting to note that the turbidity model performance of this study is comparable to the model derived using ASTER with a 15-meter resolution. Overall, we can conclude that the developed regression models using DOScorrected Landsat 8 bands can reliably estimate water parameters such as DO, pH, TSS, and BOD, while TDS and turbidity can be estimated using FLAASH-corrected Landsat 8 images. This comparison result suggests that a free satellite 
image like Landsat series can be a reliable input image if the right pre-processing method is employed.

TABLE IV. COMPARISON OF REGRESSION MODEL PERFORMANCES BETWEEN WQ MODELS

\begin{tabular}{|c|c|c|c|c|}
\hline \multirow{2}{*}{$\begin{array}{c}\text { Dependent } \\
\text { Variable }\end{array}$} & \multirow{2}{*}{$\begin{array}{l}\text { Processing } \\
\operatorname{method}(s)\end{array}$} & \multicolumn{2}{|c|}{ Model Performance } & \multirow{2}{*}{ Reference } \\
\hline & & Predictors & $\mathrm{R}^{2} \%$ & \\
\hline \multirow{3}{*}{ DO } & DOS & Turbidity and B1 & 88.5 & This study \\
\hline & DOS & B1, B3, B4, B5, B7 & 93.0 & {$[16]$} \\
\hline & N/A & B3, B6, B7 & 44.0 & [18] \\
\hline \multirow{4}{*}{ pH } & DOS, Band Ratid & B1, B5 & 89.0 & This study \\
\hline & DOS & B3, B4, B5, B6 & 81.53 & [16] \\
\hline & FLAASH & B8, B9 & 95.06 & [26] \\
\hline & N/A & B3, B4, B5, B6, B7 & 60.7 & [18] \\
\hline \multirow{5}{*}{ Turbidity } & FLAASH, PCA & $\mathrm{DO}, \mathrm{PC} 3, \mathrm{PC} 5$ & 99.8 & This study \\
\hline & DOS & $\mathrm{B} 4, \mathrm{~B} 5$ & 64.2 & [16] \\
\hline & FLAASH & $\mathrm{B} 2, \mathrm{~B} 3, \mathrm{~B} 4, \mathrm{~B} 5$ & 98.6 & [23] \\
\hline & FLAASH & B1, B2, B3 & 99.8 & [26] \\
\hline & DOS & B1, B2, B3 & 46.1 & [19] \\
\hline \multirow{3}{*}{ Conductivity } & $\begin{array}{c}\text { DOS, Band } \\
\text { Ratio } \\
\end{array}$ & B1, B5 & 67.7 & This study \\
\hline & DOS & $\mathrm{B} 2, \mathrm{~B} 3, \mathrm{~B} 4, \mathrm{~B} 6$ & 69.9 & [16] \\
\hline & FLAASH & B3, B4, B8 & 99.6 & [26] \\
\hline \multirow{4}{*}{ TSS } & DOS, PCA & PC4 & 60.1 & This study \\
\hline & DOS & B1, B2, B3 & 24.4 & [19] \\
\hline & FLAASH & $\mathrm{B} 2, \mathrm{~B} 3, \mathrm{~B} 4, \mathrm{~B} 5$ & 98.8 & [23] \\
\hline & N/A & B1, B3, B5 B6, B7 & 38.8 & [18] \\
\hline \multirow[t]{2}{*}{ TDS } & $\begin{array}{c}\text { DOS/FLAASH, } \\
\text { Band Ratio, PCA }\end{array}$ & B1, B5, PC2_SR 1 & 96.8 & This study \\
\hline & FLAASH & B3 & 99.7 & [26] \\
\hline \multirow{3}{*}{ BOD } & DOS, PCA & PC4 & 89.3 & This study \\
\hline & DOS & B1, B2, B3 & 70.7 & [14] \\
\hline & N/A & B2, B6, B7 & 47.6 & [18] \\
\hline
\end{tabular}

\section{CONCLUSION AND RECOMMENDATIONS}

This study aimed to develop RS-based models of Landsat 8 images by employing regression analysis. The results of this study showed a strong correlation between in-situ WQ readings and RS-based datasets in Tubay River. Forward regression analysis results showed that the models for turbidity, TDS, DO, $\mathrm{BOD}$, and $\mathrm{pH}$ yielded the highest $\mathrm{R}^{2}$ values of $99.3 \%, 96.8 \%$, $94.1 \%, 89.3 \%$, and $89.0 \%$, respectively, while TSS and conductivity have $\mathrm{R}^{2}$ values of only $60.1 \%$ and $67.7 \%$ respectively. These models will be beneficial in estimating WQ parameters and predicting seasonal changes. This study demonstrated promising results in estimating WQ parameters in which if further validated with multi-temporal datasets, can be considered for the development of an operational RS-based monitoring and assessment system that can be escalated at a regional and national scale. From the model comparison results, this study can conclude that it is not necessary to acquire high resolution and commercial satellite images since a free satellite image like Landsat series can be a reliable input image if the right pre-processing method is employed. We further suggest that the government's WQ monitoring campaigns will be planned to coincide with the dates of Landsat image acquisitions in the respective areas. In this way, more water characterization data with matching satellite images can be utilized in deriving more reliable empirical WQ models, as well as in the model validation.

\section{ACKNOWLEDGMENT}

This paper was supported by an Engineering Research and Development for Technology Grant of the Philippine's Department of Science and Technology. Authors would like to thank James Earl B. Cubillas for his technical assistance and the Center for Resource Assessment, Analytics, and Emerging Technologies of Caraga State University for providing a workspace to download and pre-process the Landsat images.

\section{REFERENCES}

[1] F. Mushtaq, A. C. Pandey, "Assessment of land use/land cover dynamics vis-a-vis hydrometeorological variability in Wular Lake environs Kashmir Valley, India using multitemporal satellite data", Arabian Journal of Geosciences, Vol. 7, No. 11, pp. 4707-4715, 2014

[2] F. Mushtaq, M. G. Nee Lala, A. C. Pandey, "Assessment of pollution level in a Himalayan Lake, Kashmir, using geomatics approach", International Journal of Environmental Analytical Chemistry, Vol. 95, No. 11, pp. 1001-1013, 2015

[3] M. Gholizadeh, A. Melesse, L. Reddi, "A Comprehensive Review on Water Quality Parameters Estimation Using Remote Sensing Techniques", Sensors, Vol. 16, No. 8, p. 1298, 2016

[4] S. J. Goetz, N. Gardiner, J. H. Viers, "Monitoring freshwater, estuarine and near-shore benthic ecosystems with multi-sensor remote sensing: An introduction to the special issue", Remote Sensing of Environment, Vol. 112, No. 11, pp. 3993-3995, 2008

[5] J. Kibena, I. Nhapi, W. Gumindoga, "Assessing the relationship between water quality parameters and changes in landuse patterns in the Upper Manyame River , Zimbabwe", Physics and Chemistry of the Earth, Parts A/B/C, Vol. 67-69, pp. 153-163, 2014

[6] E. Alparslan, C. Aydoner, V. Tufekci, H. Tufekci, "Water quality assessment at Omerli Dam using remote sensing techniques", Environmental Monitoring and Assessment, Vol. 134, No. 1-3, p. 391, 2007

[7] D. G. Hadjimitsis, M. G. Hadjimitsis, L. Toulios, C. Clayton, "Use of space technology for assisting water quality assessment and monitoring of inland water bodies", Physics and Chemistry of the Earth, Parts A/B/C, Vol. 35, No. 1-2, pp. 115-120, 2010

[8] V. Markogianni, D. Kalvas, G. P. Petropoulos, E. Dimitriou, "An appraisal of the potential of Landsat 8 in estimating chlorophyll-a, ammonium concentrations and other water quality indicators", Remote Sensors, Vol. 10, No. 7, pp. 1-22, 2018

[9] Y. A. El-Amier, A. A. Elnaggar, M. A. El-Alfy, "Evaluation and mapping spatial distribution of bottom sediment heavy metal contamination in Burullus Lake, Egypt", Egyptian Journal of Basic and Applied Sciences, Vol. 4, No. 1, pp. 55-66, 2017

[10] A. S. Jasrotia, A. Majhi, S. Singh, "Water Balance Approach for Rainwater Harvesting using Remote Sensing and GIS Techniques, Jammu Himalaya, India", Water Resources Management, Vol. 23, No. 14, pp. 3035-3055, 2009

[11] P. H. Gowda, J. L. Chavez, P. D. Colaizzi, S. R. Evett, T. A. Howell, J. A. Tolk, "ET mapping for agricultural water management: present status and challenges", Irrigation Science, Vol. 26, No. 3, pp. 223-237, 2008

[12] I. Klein, A. J. Dietz, U. Gessner, A. Galayeva, A. Myrzakhmetov, C. Kuenzer, "Evaluation of seasonal water body extents in Central Asia over thepast 27 years derived from medium-resolution remote sensing data", International Journal of Applied Earth Observation and Geoinformation, Vol. 26, No. 1, pp. 335-349, 2014

[13] C. Ye, "Extraction of water body in before and after images of flood using Mahalanobis distance-based spectral analysis", Remote Sensing, Vol. 31, No. 4, pp. 293-302, 2015

[14] Y. Wang, H. Xia, J. Fu, G. Sheng, "Water quality change in reservoirs of Shenzhen, China: detection using LANDSAT/TM data", The Science of the Total Environment, Vol. 328, No. 1-3, pp. 195-206, 2004

[15] R. Swain, B. Sahoo, "Improving river water quality monitoring using satellite data products and a genetic algorithm processing approach", 
Sustainability of Water Quality and Ecology, Vol. 9-10, pp. 88-114, 2017

[16] L. C. Gonzalez-Marquez, F. M. Torres-Bejarano, A. C. TorregrozaEspinosa, I. R. Hansen-Rodriguez, H. B. Rodriguez-Gallegos, "Use of LANDSAT 8 images for depth and water quality assessment of El Guajaro reservoir, Colombia", Journal of South American Earth Sciences, Vol. 82, pp. 231-238, 2018

[17] A. El-Zeiny, S. El-Kafrawy, "Assessment of water pollution induced by human activities in Burullus Lake using Landsat 8 operational land imager and GIS", The Egyptian Journal of Remote Sensing and Space Science, Vol. 20, Suppl. 1, pp. S49-S56, 2017

[18] A. M. El Saadi, M. M. Yousry, H. S. Jahin, "Statistical estimation of Rosetta branch water quality using multi-spectral data", Water Science, Vol. 28, No. 1, pp. 18-30, 2014

[19] A. Kulkarni, "Water Quality Retrieval from Landsat TM Imagery", Procedia Computer Science, Vol. 6, pp. 475-480, 2011

[20] V. Markogianni, D. Kalivas, G. Petropoulos, E. Dimitriou, "Analysis on the feseability of L8 for WQPs assessment", International Journal of Environmental, Chemical, Ecological, Geological and Geophysical Engineering, Vol. 11, No. 9, pp. 906-914, 2017

[21] E. Kontopoulou, P. Kolokoussis, K. Karantzalos, "Water quality estimation in Greek lakes from Landsat 8 multispectral satellite data", European Water, Vol. 58, pp. 191-196, 2017

[22] M. Waxter, Analysis of Landsat Satellite Data to Monitor Water Quality Parameters in Tenmile Lake, Oregon, MSc Thesis, Portland State University, 2014

[23] T. S. Kapalanga, Assessment and Development of Remote Sensing Based Algorithms For Water Quality Monitoring in Olushandja Dam, North-Central Namibia, MSc Thesis, University of Zimbabwe, 2015

[24] D. Barrett, A. Frazier, "Automated Method for Monitoring Water Quality Using Landsat Imagery", Water, Vol. 8, No. 6, p. 257, 2016

[25] V. Kumar, A. Sharma, A. Chawla, R. Bhardwaj, A. K. Thukral, "Water quality assessment of river Beas, India, using multivariate and remote sensing techniques", Environmental Monitoring and Assessment, Vol. 188, No. 3, p. 137, 2016

[26] K. W. Abdelmalik, "Role of statistical remote sensing for Inland water quality parameters prediction", The Egyptian Journal of Remote Sensing and Space Science, Vol. 21, No. 2, pp. 193-200, 2018

[27] R. Swain, B. Sahoo, "Mapping of heavy metal pollution in river water at daily time-scale using spatio-temporal fusion of MODIS-aqua and Landsat satellite imageries", Journal of Environmental Management, Vol. 192, pp. 1-14, 2017

[28] Environmental Management Bureau-Caraga Region, Tubay River Water Quality Assessment, 2015

[29] G. Chander, B. Markham, D. Helder, "Summary of Current Radiometric Calibration Coefficients for", Remote Sensing of Environment, Vol. 1, No. 2009, pp. 1-24, 2009

[30] S. M. Adler-Golden, A. Berk, L. S. Bernstein, S. Richtsmeier, P. K. Acharya, M. W. Matthew, G. P. Anderson, C. L. Allred, L. S. Jeong, J. H. Chetwynd, "FLAASH, a MODTRAN4 atmospheric correction package for hyperspectral data retrievals and simulations", in: Proceedings of the 7th Annual JPL Airborne Earth Science Workshop, Vol. 97, JPL Publication, 1998

[31] P. S. Chavez, "An improved dark-object subtraction technique for atmospheric scattering correction of multispectral data", Remote Sensing of Environment, Vol. 24, No. 3, pp. 459-479, 1988

[32] G. Srivastava, P. Kumar, "Water quality index with missing parameters", International Journal of Research in Engineering and Technology, Vol. 2, No. 4, pp. 609-614, 2013

\section{AUTHORS PROFILE}

Michelle V. Japitana is an Associate Professor the College Engineering and GeoSciences (CEGS), Caraga State University and is currently a Doctor of the Engineering Program of the University of San Carlos. She received her BSc degree in Geodetic Engineering from Caraga State University in 2003 and her MSc in Remote Sensing from the University of Philippines. Her research interests include resource mapping, environmental monitoring, and RS-GIS applications.

Marlowe Edgar C. Burce is an Associate Professor of the University of San Carlos. He finished his PhD (2012) and MSc (2009) in Biosystems Sustainability at Hokkaido University, Japan. He also received his MSc in Information Technology in 2005 and BSc in Computer Engineering at the University of San Carlos. His research interests include precision agriculture, field robotics, remote sensing, management information systems, application and systems programming, programmable logic controllers, microcontrollers and embedded systems. 